\title{
Kristal Yöneliminin ve Sıcaklığın Cu Nano Telinin Mekanik Özelliklerine Etkisinin Moleküler Dinamik Benzetimi ile İncelenmesi
}

\section{Investigation of the Effect of Crystal Orientation and Temperature on Mechanical Properties of Cu Nanowire by Molecular Dynamics Simulation}

\author{
Sefa Kazanç ${ }^{{ }^{*}}$ \\ ${ }^{1}$ Fırat Üniversitesi Eğitim Fakültesi Matematik ve Fen Bilimleri Eğitimi Bölümü, Elazığ, TÜRKiYE \\ Sorumlu Yazar / Corresponding Author * skazanc@firat.edu.tr \\ Geliş Tarihi / Received: 09.06.2021 \\ Araștırma Makalesi/Research Article \\ Kabul Tarihi / Accepted: 27.08.2021 \\ DOI:10.21205/deufmd.2022247003
}

Atıfs șekli/How to cite: KAZANC S.(2022). Kristal Yöneliminin ve Sıcakliğın Cu Nano Telinin Mekanik Özelliklerine Etkisinin Moleküler Dinamik Benzetimi ile Incelenmesi. DEUFMD, 24(70), 19-28.

Öz

Bu çalışmada $<100>$, $<110>$ ve $<111>$ yüksek simetrili kristalografik yönelimleri boyunca Cu nano teline uygulanan tek eksenli gerilme deformasyonunun mekanik özelliklere etkisi Moleküler Dinamik (MD) benzetim yöntemi ile incelendi. Atomlar üzerine etki eden kuvvetler çok cisim etkileşmelerini içeren Gömülmüş Atom Metodu (GAM) potansiyel fonksiyonunun türevinden elde edildi. Farklı kristal yönelimlerine sahip $\mathrm{Cu}$ model nano tellerin farklı sıcaklıklar altında zorzorlanma eğrileri, elastiklik modülü (E), akma zoru değerleri belirlendi. Elde edilen atomik görüntüler ve genel komşu analiz metodu (Common Neighbor Analysis-CNA) kullanılarak uygulanan gerilme sonucu nano tellerde meydana gelen plastik deformasyonun bütün yönelimler için Shockley kısmi dislokasyonların aktif hale geçmesi ve yığılım kusurları sonucu meydana geldiği tespit edildi. Ayrıca $<100>$ ve $<110>$ yönelimleri için akma meydana geldiğinde ikiz yapılarının oluşumu belirlendi. Kristal yönelimlerinin nano telin mekanik özellikleri üzerinde önemli bir etkiye sahip olduğu görüldü.

Anahtar Kelimeler: Kristal yönelimi, nano tel, mekanik özellikler, moleküler dinamik.

\begin{abstract}
In this study, the effect of uniaxial tensile strain applied to Cu nanowire along the $\langle 100\rangle,\langle 110\rangle$ and $<111>$ highly symmetric crystallographic orientations on the mechanical properties was investigated by Molecular Dynamics (MD) simulation method. The forces acting on atoms were obtained from the derivative of the Embedded Atom Method (EAM) potential function, which includes many-body interactions. The Stress-strain curves, Young's modulus (E), yielding strength, and values of $\mathrm{Cu}$ model nanowires with different crystal orientations were determined under different temperatures. By using the obtained atomic images and the Common Neighbor Analysis method (CNA), it was determined that the plastic deformation occurred in the nanowires as a result of the stress applied as a result of the activation of Shockley partial dislocations and stacking faults defects for all orientations. In addition, for the $<100>$ and $<110>$ orientations, the formation of twin
\end{abstract}


DEÜ FMD 24(70), 19-28, 2022

structures was determined when yielding occurred. It was seen that the crystal orientations have a significant effect on the mechanical properties of the nanowire.

Keywords: Crystal orientation, nanowire, mechanical properties, molecular dynamic

\section{Giriş}

Nano bilimin ve nano teknolojinin son yıllardaki hızlı gelişimi, metal nano tellerini gün geçtikçe daha önemli hale getirmiştir. Nano ölçekte düșük boyutlu tek kristallerin deformasyon davranışı, onların hacimsel yapılı benzerlerinden farklılık göstermektedir. Büyük yüzey alanı/hacim oranı ve düşük yoğunluklu kusurlara sahip nano yaplar hacimli (bulk) tek kristal yapılardan farklı özellikler sergilemesine neden olur [1, 2]. Sadece 4 atomik düzlemden oluşan en ince metal $\mathrm{Au}$ nano tel, çok yüksek vakum elektron mikroskopunda elektron ışın demeti kullanılarak Kondo ve Takayanagi tarafından üretilmiștir [3]. Metal nano tellerin mekanik özelliklerinin belirlenmesi nanoelektromekanik sistemlerin tasarlanması ve üretimi için açısından son derece önemlidir. Değişik metalik nano tellerin elektriksel, mekanik, optik ve termal özelliklerini belirlemek için birçok deneysel çalışma yapılmıștır [4-6]. Nano tellerin gerek termodinamik gerekse mekanik özellikleri sıcaklık, tel yapısı, kristalografik yönelim, uygulanan sıkıștırma-zorlanma oranı, yüzey ve sınır şartlarından önemli derecede etkilenmektedir. $\alpha$-Fe nano telinin yönelime bağlı deformasyon davranışının incelendiği çalışmada, meydana gelen plastik deformasyonun farklı kristal yönelimlerinde, dislokasyon kayması ve ikizlenme gibi farklı mekanizmalarla oluștuğu belirlenmiștir [7]. Au nano telinin mekanik özelliklerine kristal yöneliminin etkisinin incelendiği bir başka çalıșmada elastiklik modülünün, akma zorunun, Schmidt faktörünün yönelime kuvvetli bir șekilde bağlı olduğu ve plastik deformasyonun Shockly kismi dislokasyonlarının aktivitesiyle meydana geldiği tespit edilmiştir [8]. Değişik metal nano tellerin elastik özellikleri, akma zoru, yüzey-zor etkili faz dönüşümleri Gall ve arkadașları tarafından detaylıca çalıșılmıștır. Nano ölçekteki Au' nun sıkıştırma, germe ve kesme deformasyonunun atomik seviyede görselleștirilmesi yüksek çözünürlüklü geçirmeli elektron mikroskobu ile gerçekleștirilmiștir. [9]. Tschopp ve arkadașları $[10,11]$ farklı yönelimli tek kristal $\mathrm{Cu}$ elementindeki sıkıştırma-germe asimetrisini incelediler. Yaptıkları çalıșmada sıkıștırmanın germeden daha yüksek bir akma zoru ürettiğini belirlediler.

Deneysel çalıșmaların yanı sıra atomik seviyede maddelerin yapı ve özelliklerinin teorik olarak incelendiği bilgisayar benzetim çalıșmaları son derece önemli bir hale gelmiștir. Bilgisayar teknolojisinin ve sayısal hesaplama yöntemlerinin hızlı gelișimi, bununla birlikte gerçekçi atomlararası potansiyellerin varlığı, MD benzetim yöntemini nano materyallerin mekanik davranışlarını incelemek için etkili bir araç haline getirmiștir. Metalik nano tellerin mekanik davranıșlarını anlamak için değișik GAM fonksiyonlarının kullanıldığı klasik MD benzetimleri ve yoğunluk fonksiyonu teorisi üzerine kurulu ilk prensip (first-principles) metodu gibi farklı yaklaşımlarla birçok teorik çalışma yapılmıştır [12-14]. Bununla birlikte ilk prensip hesaplamaları yüksek işlemci gücüne ihtiyaç duymaktadır. Yaplan benzetim çalışmalarında elde edilen sonuçların deneysel değerlerle uyumluluğu model sistemde atomlar arasındaki etkileșmeleri ifade eden potansiyel enerji fonksiyonun seçimine bağlıdır. Farklı sistemlerin modellenmesi için geliştirilin birçok potansiyel fonksiyonu bulunmaktadır [15-17]. Çok cisim etkileşmelerini içeren GAM, sadece yapısı ve etkili sonuç vermesinden dolayı benzetim çalışmalarında en çok tercih edilen potansiyel fonksiyonlarındandır. [18, 19]. Literatürde nano teller ile ilgili MD benzetim yöntemi kullanılarak yapılan birçok çalışma bulunmaktadır [20-22].

$\mathrm{Cu}$ elementi yüksek derecede elastik anizotropiye sahip olduğundan bu çalıșma için seçilmiştir. Mekanik özelliklerin kristal yönelimlerinden etkilenmesi bu tür elementlerin özellikle nano teknolojik uygulamarında son derece önem arz etmektedir [11]. Bu çalıșmada farklı kristolografik yönelimlerde oluşturulan $\mathrm{Cu}$ nano teline $10 \mathrm{~K}$, $100 \mathrm{~K}, 300 \mathrm{~K}, 500 \mathrm{~K}, 700 \mathrm{~K}$ ve $900 \mathrm{~K}$ sicaklık değerlerinde uygulanan tek eksenli germe deformasyonunun elastiklik modülü, akma zoru gibi mekanik davranışlar üzerindeki etkisi MD 
benzetim metodu ile incendi. Calıșmada büyük ölçekli atomik/moleküler kitlesel paralel simülatör (Large-scale Atomic/Molecular Massively Parallel Simulator-LAMMPS) açık kaynak kodlu MD benzetim programı kullanıldı [23]. Atomlar arası etkileşmeler GAM potansiyel fonksiyonu ile belirlendi. Elastik bölge dıșında meydana gelen plastik deformasyon mekanizmasının incelenmesi için CNA analiz yöntemi kullanıldı.

\section{Materyal ve Metot}

Klasik MD benzetim yönteminde $\mathrm{N}$ atomlu bir sistemin hareket denklemleri aşağıda verilen Lagrange fonksiyonundan elde edilir.

$L_{P R}\left(\mathbf{r}^{N}, \dot{\mathbf{r}}^{N}, \mathbf{h}, \dot{\mathbf{h}}\right)=\frac{1}{2} \sum_{i=1}^{N} m_{i}\left(\dot{\mathbf{s}}_{i}^{t} \mathrm{G} \dot{\mathbf{s}}_{i}\right)$

$-\sum_{i=1}^{N} \sum_{j>i}^{N} \phi\left(\left|\mathbf{h} \mathbf{s}_{i j}\right|\right)+\frac{1}{2} M \operatorname{Tr}\left(\dot{\mathbf{h}}^{t} \dot{\mathbf{h}}\right)-P_{e x t} V$

si, h, G ve $P_{\text {ext }}$ parametreleri sirasiyla skalalandırılmış koordinat, hesaplama hücresinin eksenleri, metrik tensör ve diş basıncı tanımlamaktadır.

Germe deformasyonu sürecinde nano telin ekseni boyunca zor, denklem (2) tarafindan hesaplanmaktadır [24, 25].

$$
\boldsymbol{\pi}=V^{-1}\left[\sum_{i=1}^{N} m_{i} \vartheta_{i} \vartheta_{i}-\sum_{i=1}^{N} \sum_{j>i}^{N} \frac{F_{i j}}{r_{i j}} \mathbf{r}_{i} \cdot \mathbf{r}_{j}\right]
$$

$\mathrm{Bu}$ çalıșmada model nano tel sisteminde $\mathrm{Cu}$ atomları başlangıç konumları olarak fcc örgü noktalarına yerleştirildi. Periyodik sınır şartları sadece $\mathrm{x}$ doğrultusu boyunca uygulanırken y ve $\mathrm{z}$ doğrultuları serbest bırakıldı. İlk hızlar Maxwell-Boltzman hız dağılımına uyun olacak şekilde rasgele belirlendi. Parçacık sayısının, hacmin ve sıcaklığın sabit tutulduğu NVT istatistik topluluğu kullanıldı Hareket denklemlerinin sayısal çözümü Verlet algoritmasının hız formu ile yapıldı. İntegrasyon adım aralığı 5 fs olarak belirlendi. Germe deformasyonu uygulanmadan önce bütün yönelimler için model nano tel sistemi 50000 MD adımı dengeletildi. Tüm çalışma boyunca model nano tel sistemine uygulanan zorlanma oranı $1 \times 10^{10} \mathrm{~s}^{-1}$ olarak seçildi.

Model hesaplama hücresinde $\mathrm{Cu}$ atomları arasındaki etkileşmeleri hesaplamak için GAM potansiyel fonksiyonu kullanıldı. Potansiyel ile ilgili detaylar literatürden bulunabilir [26].

$\mathrm{Bu}$ çalıșmada $\mathrm{Cu}$ nano telinin mekanik özelliklerine kristal yöneliminin etkilerini belirlemek için yüksek simetrili <100>, <110> ve $<111>$ örgü yönelimi seçildi. $\mathrm{Cu}$ nano tel yapısı $<100>$, <110> ve <111> yönelimleri için sirasiyla 4647, 4857 ve 4903 atomdan meydana gelmektedir. Nano telin x yönündeki uzunluğu $10,8 \mathrm{~nm}, \mathrm{y}$ ve z yönlerinde 2,17 nm dir. Bütün çalıșmalarda farklı yönelimli $\mathrm{Cu}$ nano teline germe deformasyonu sadece $\mathrm{x}$ ekseni boyunca uyguland. Model nano tel sisteminin $\mathrm{x}-$ doğrultusu boyunca iki uç bölgesindeki birkaç atomik tabaka sabitlendi. Ara bölgede kalan atomların dinamik davranıșına izin verildi. Deneysel çekme yöntemine uygun olması açısından sabit uçlardan biri hareketsiz tutulurken diğer uca çekme gerilmesi uygulandı.

MD çalışmalarında fcc, hcp, bcc gibi mikro yapıların belirlenmesi ve onların gelișimlerinin incelenmesi oldukça önemlidir. Bu yapıların belirlenmesi amacıyla birçok sayısal analiz yöntemi geliştirilmiştir. Bu yöntemlerin temel hedefi her bir parçacığa bir yapısal tür atamaktır. Ayrıca bu yöntemler yerel bir yapıyı idealleștirilmiş bir yapıyla eşleştirerek, ne kadar yakın olduklarını belirlemeye çalıșır. MD benzetim çalışmalarında yapı karakterizasyon yöntemleri olarak merkez simetri parametre analizi (centrosymmetry paramatre analysis), genel yakın komşu analizi (common neighbohr analysis-CNA), bağ-yönelim analizi (bond-order analysis), bağ açı analizi (bond-angle analysis), Honeycutt-Andersen ve Voronoi analizi oldukça sık kullanılmaktadır [27, 28]. Bu çalıșmada atomik konumların görselleștirilmesi ve CNA analizi OVITO programı ile gerçekleştirildi [29].

\section{Bulgular}

$\mathrm{Bu}$ çalıșmada üç yüksek simetri doğrultusu boyunca atomların fcc örgü noktalarına yerleștirildiği $\mathrm{Cu}$ nano tel model sistemine $\mathrm{x}$ ekseni boyunca uygulanan gerilme deformasyonun mekanik özellikler üzerindeki etkileri incelenmeye çalıșıldı. Kristal yönelim etkilerini belirlemek için $\langle 100\rangle,\langle 110\rangle$ ve $<111>$ üç yüksek simetri örgü yönelimi dikkate alındı. Șekil 1 de bu üç farklı kristal yönelimine sahip $\mathrm{Cu}$ nano telllerin başlangıç yapıları verilmiștir. Eksensel zorlanma ișlemi, nano telin soldaki sabit uç hareketsiz tutularak, sağdaki sabit uç $1 \times 10^{10} \mathrm{~s}^{-1}$ zorlanma oranı ile 
gerilerek uygulandı. Nano telin her iki sabit ucu ardaşık üç (100) atomik düzlemlerinde bulunan atomlardan oluşmaktadır.

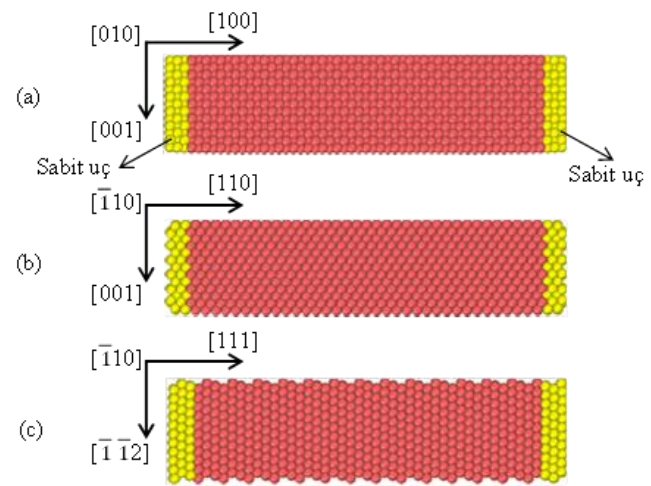

Şekil 1: (a) <100>, (b) <110> ve (c) <111> kristal yönelimine sahip $\mathrm{Cu}$ nano tellerinin başlangıç atomik görüntüleri. Kırmızı renkli küreler dinamik atomları, sarı renkli küreler sabit uç olarak tanımlanan hareketsiz sınır atomlarını göstermektedir.

Șekil 2 de $\langle 100\rangle$, $<110\rangle$ ve $<111\rangle$ Cu nano tellerinin $300 \mathrm{~K}$ sıcaklık değerlerinde uygulanan eksensel zorlanmaya karşı mekanik tepkileri verilmiştir. Kristal yöneliminin bir fonksiyonu olarak $\mathrm{Cu}$ nano telleri elastik anizotropi davranıșı sergilemektedir. Zor-zorlanma eğrisinden elastiklik modülünün, akma zorunun, plastik deformasyon davranışının kristal yönelimine kuvvetli bir şekilde bağlı olduğu açıkça görülmektedir. <100> ve <110> nano telleri için elastik deformasyonun meydana geldiği zorlanma bölgesinde sırasıyla yukarı ve aşağı yönlü bir eğrisellik görülmektedir. Bunun aksine <111> nano telinin zor-zorlanma eğrisi doğrusal elastikliğe en yakın olandır. Zor-zorlanma eğrisinin elastik bölgede doğrusallıktan saparak aşağı doğru eğrisel olması elastik yumuşamanın, aynı şekilde eğrinin yukarı doğru olması elastik sertleşmenin bir göstergesidir. Elastik yumuşama ve elastik sertleșme elastik bölgede yüksek zorlanmalarda doğrusal olmayan zorzorlanma tepkisini tanımlamada kullanılır. Burada elastiklik modülü saf elastik şartlarda beklenen değerden ya daha düşük veya daha yüksektir [19].

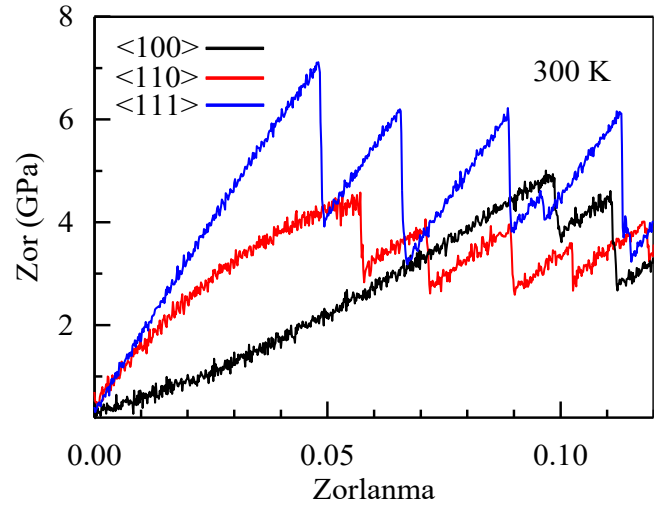

Sekil 2: Farklı kristal yönelimli nano teller için $300 \mathrm{~K}$ sicaklık değerinde elde edilen zorzorlanma eğrileri.

Şekil 2 de $1 \times 10^{10} \mathrm{~s}^{-1}$ zorlanma oranı ile x ekseni boyunca çekilen üç kristal yönelimine sahip nano teller için zorlanmanın $(\varepsilon)$ belirli bir değerine kadar zorda bir artış görülmektedir. Elastik bölge olarak bilinen bu bölgede zorlanma, $<100>$ nano teli için $\varepsilon=0,097(0,056)$, $<110>$ nano teli için $\varepsilon=0,057(0,041)$ ve $<111>$ nano teli için $\varepsilon=0,048 \quad(0,037)$ değerine ulaștığında zorda ani bir düşüş gözlenmektedir. Parantez içindeki ifadeler deneysel değerleri göstermektedir [18]. Zor değerinde ani düşüş başlamadan önce eğrinin maksimum değeri, plastik şekil değişimin başladığı akma zoru olarak bilinmektedir. Zor değerindeki bu keskin azalmanın yapı içerisinde dislokasyonların çekirdeklenmesinden dolayı olduğu bilinmektedir. Daha sonra zor-zorlanma eğrisi testere diși gibi bir görünüm sergiler. $\mathrm{Bu}$ değişim sebebinin çekirdeklenen dislokasyonların büyümesi ve yayılmasından dolayı olduğu söylenebilir [30]. MD benzetim çalışmasından elde edilen akma zoru değerleri $<100>,\langle 110\rangle,<111>$ yönelimleri için sırasıyla $4,95 \mathrm{GPa}(4,51 \mathrm{GPa}), 4.45 \mathrm{GPa}(4,15 \mathrm{GPa})$ ve 7,12 GPa $(4,88 \mathrm{GPa})$ olarak belirlenmiștir [18]. Parantez içindeki ifadeler deneysel çalışmalardan elde edilen değerleri göstermektedir. Elastiklik modülü (E), elastik bölgede zor-zorlanma eğrisinin doğrusal değişiminin regrasyon analizi sonucu belirlenmiștir. <100> nano kristali için elastiklik modülü $53,8 \mathrm{GPa},<110>$ nano teli için $101,6 \mathrm{GPa}$ ve $<111>$ nano teli için $146,2 \mathrm{GPa}$ olarak tespit edilmiștir. Elastiklik modülünün $\mathrm{E}_{<111>}>\mathrm{E}_{<110>}>\mathrm{E}_{<100>}$ şeklinde farklı değerler alması E'nin kristal yönelimine kuvvetli bir 
DEÜ FMD 24(70), 19-28, 2022

șekilde bağlılığını gösterir. <100>, <110>, $<111>$ kristal yönelimli nano teller için elastiklik modülünün deneysel değerleri sirasiyla $80,04 \mathrm{GPa}, 102,3 \mathrm{GPa}$ ve $137,5 \mathrm{GPa}$ olarak belirlenmiştir [31]. <110> nano teli için benzetim çalışmasından elde edilen elastiklik modülü deneysel değere oldukça yakındır. Bu karşılık <100> ve <111> nano telleri için belirlenen sonuçlar deneysel değerlerden sapma göstermektedir. $\mathrm{Bu}$ tutarsızlığın sebeplerinden biri olarak termal şartlardaki farklılıklar gösterilebilir. Cu'nun elastik anizotropisi deneysel olarak elde edilen elastiklik modülünün değeri üzerinde bazı değişikliklere de sebep olabilir. Ayrıca model nano tel sistemimizde herhangi bir yapı kusurunun bulunmaması, buna karșllık deneysel olarak hazırlanan $\mathrm{Cu}$ nano telinde safsızlık atomları ve kusurların bulunabilme ihtimali elastiklik modülündeki bu farklılığa sebep olabilir. $\mathrm{Bu}$ durumlar göz önüne alındığında hesaplamalardan elde edilen elastiklik modülü değerinin kabul edilebilir sınırlar içerisinde olduğu söylenebilir. Johnson tarafından geliştirilen GAM potansiyeli kullanılarak yapılan bir çalışmada elastiklik modülü $<100>,<110>$ ve $<111>$ nano telleri için sirasiyla 100,16 GPa, 115,69 GPa ve164,76 GPa olarak belirlenmiștir [18]. Calıșmamızda kullanılan GAM ile elde edilen elastiklik modülünün deneysel değerlerle daha uyumlu sonuçlar ürettiği görülmektedir [31].

Üç farklı kristal yönelimine sahip $\mathrm{Cu}$ nano tel model sistemine $10 \mathrm{~K}, 100 \mathrm{~K}, 300 \mathrm{~K}, 500 \mathrm{~K}, 700$ $\mathrm{K}$ ve $900 \mathrm{~K}$ sicaklık değerlerinde germe deformasyonu uygulanarak sicaklığın mekanik davranışlar üzerindeki etkisi belirlenmeye çalışıldı. Şekil 3'te elastiklik modülünün sıcaklıkla değişimi verilmiştir. Üç kristal yönelimi içinde elastiklik modülünün sıcaklık artıșına karșı duyarlı olduğu açıkça görülmektedir. Bu değișim artan sıcaklıkla bağ kuvvetlerinde meydana gelen önemli derecede zayıflamadan kaynaklanmaktadır. Genel olarak elastiklik modülü sıcaklık artışıyla doğrusal olarak bir azalma göstermektedir. Elde ettiğimiz sonuçlardan bu değișimin her üç yönelim içinde doğrusal bir azalma sergilediği belirlenmiştir. Bu durum teorik olarak şu şekilde açılanabilir. Elastiklik modülünün tanımına göre, denge konumuna göre potansiyelin birinci türevi elastiklik modülüne benzetilebilir. Eğer Lennard-Jones potansiyelinin birinci türevi göz önüne alınırsa kesinti süreci basitleştirilebilir ve elastiklik modülü $1 / \mathrm{rc}^{\mathrm{c}}$ ile orantılıdır. Sonuc olarak sıcaklığın artması ile atom konumlarının denge mesafeleri artar. Bu durum elastiklik modülünün azalmasını etkiler. Bu nedenle hem zor-zorlanma eğrisinin değişimi hem de elastiklik modülündeki düşüş, sıcaklık artışı ile daha az kararlı kristal yapının meydana geldiğini gösterir [18].

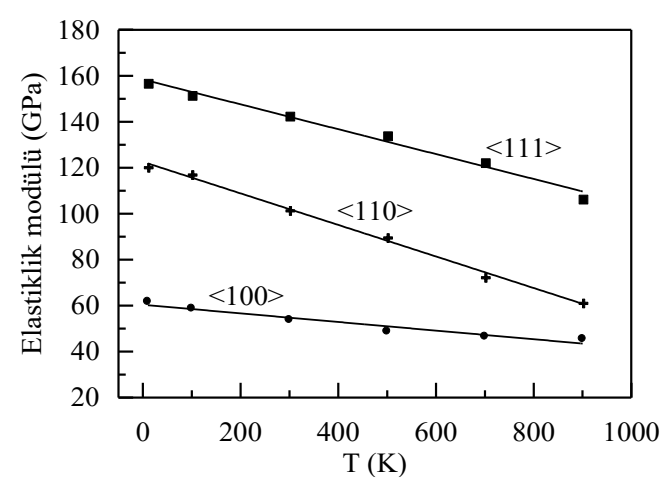

Şekil 3: Sıcaklıkla elastiklik modülünün kristal yönelimine göre değişimi.

Şekil 4'te üç farklı kristal yönelimine sahip $\mathrm{Cu}$ nano telinin sıcaklıkla akma zorundaki değişimi verilmiștir. Geri döndürülemeyen șekil değişiminin başlamasını ifade eden akma zorunun sıcaklık artışı ile değişiminin doğrusal bir șekilde gerçekleşmediği görülmektedir. Sıcaklık artışı model sistemin entropisinin artmasına sebep olmuştur. Atomlar daha büyük titreșim genliklerine ve kinetik enerjiye sahiptirler. Bunun sonucu olarak enerjileri artan daha çok sayıdaki atom aktivasyon enerji engeli aşarak yapısal kusurların oluşumuna sebep olur. Bu da zor değerindeki azalmanın sebebi olarak verilebilir [32].

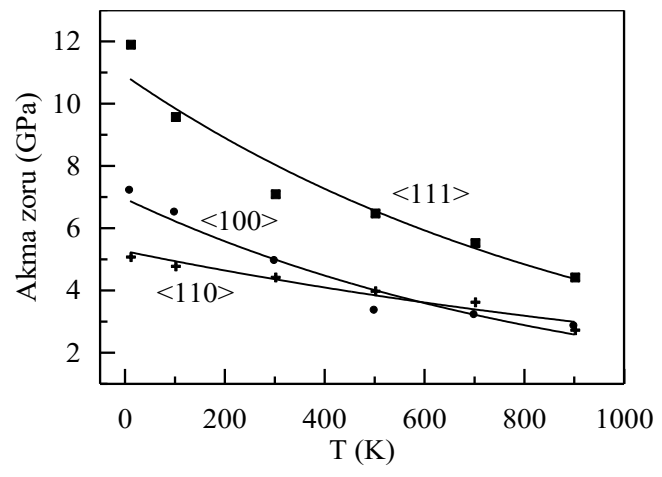

Sekil 4: Sicaklıkla akma zorunun kristal yönelimine göre değișimi. 
DEÜ FMD 24(70), 19-28, 2022

Farklı kristal yönelimine sahip model nano tel sistemlerinde tek eksenli gerilme sonucu meydana gelen plastik deformasyonun mekanizması OVITO programıla görselleştirilen atomik konumlar ve Honeycut ve Andersen tarafından önerilen CNA topolojik analiz yöntemi ile belirlenmeye çalışıldı. CNA analiz yönteminde model sistemde seçilen her referans atomu, bir atom ve en yakın komșuları arasındaki bağlar tarafından belirlenen bölgesel kristal yapılara göre sınıflandırılır. Bölgesel fcc düzenindeki atomlar fcc atomları, bölgesel bcc düzenindeki atomlar bcc atomları ve hcp düzenindeki atomlar fcc kristalinde olușan yığılma kusuru yapılar olarak görülen hcp atomları olarak sınıflandırılırken, bu düzenlere uymayan atomlar ise "diğer" atomlar olarak adlandırılmaktadır [33].

Şekil 5(a-c)'de $10 \mathrm{~K}$ sıcaklık değeri için üç farklı kristal yöneliminde sahip nano tel yapılarının zor-zorlanma eğrileri verilmiștir. <110> ve $<111>$ yönelimli nano tellerin sonuçlarıyla karşılaştırmak amacıyla ilk önce $<100>\mathrm{Cu}$ nano telinin plastik deformasyonunun yapısal gelişimi incelenmiştir. Şekil 5(a)'daki <100> kristal yönelimi için elde edilen zor-zorlanma eğrisinde akma zoru olarak bilinen 1 noktası için (100) düzlem kesitinden alınan nano telin atomik konumları Sekil 6(a) da verilmiștir. Şekilde noktalı kapalı eğrisel yüzeyle gösterilen bölgede kusursuz fcc kristal yapı içerisinde CNA analizinde "diğer" olarak adlandırılan, beyaz renkli atomlarla sembolize edilen ve herhangi bir atom türü olarak tanımlanmayan yapıların oluşumu görülmektedir. Yüzeye yakın bu bölgede zorlanmanın kritik bir değere ulaşmasıyla fcc atomlarının yeniden düzenlenmeye bașlaması, dislokasyonların çekirdeklenmesinin bir göstergesi olarak ifade edilebilir. Şekil 5(a) da 2 nolu bölgeye karşılık gelen zorlanma değerine ulașıldığında elde edilen atomik görüntüler Şekil 6(b) de verilmiştir. Artan zorlanma değeriyle birlikte tanımlanamayan atomlardan oluşan bölgenin yapı içerisinde genişlediği ve hcp atomlarından oluşan düzlemlerin meydana gelmeye başladığ görülmektedir. fcc kristalindeki atomlarının dizilim hatası olarak bilinen hcp atomları bir araya gelerek model nano tel içerisinde oklarla gösterilen bölgelerde yığılım kusurlarını olușturmaktadır. Zorlanma değerinin artmasıyla hcp atomlarından olușan yığılım kusuru düzlemlerinin nano telin bir ucundan diğer ucuna yayıldığı açıkça görülmektedir.
Model $\mathrm{Cu}$ nano tel sistemine (nano tel yapısındaki MD hesaplama hücresi) tek eksenli gerilme deformasyonu uygulanması sonucu elastik şekil değişiminin meydana geldiği zorlanma bölgesi geçilip kalıcı şekil değişiminin meydana geldiği kritik zorlanma değerine (Şekil 5(a)'da 3 noktası) ulașıldığında fcc kristal yapı içerisinde hcp atomlarından oluşan bitişik düzlemler görülmektedir. hcp atomlarından oluşan bu düzlemler yapı içerisinde Shockley kısmi dislokasyonlarının aktif hale geçmesi sonucu olușan yığılma kusurlarının bir göstergesi olarak ifade edilmektedir [8, 30]. Zorlanmanın artmasıyla tüm nano tel boyunca bașka Shockley kısmi dislokasyonlarının çekirdeklenmesi ve yapı içerisinde yayılması yığılım kusurlarının artmasına yol açmaktadır [7]. Şekil 5(a) da 4 ve 5 numaralı noktaya karşılık gelen zorlanma değerinde elde edilen atomik konumlar Şekil 6 (d-e) de verilmiştir. Bu zorlanma değerlerine ulaşıldığında sırasıyla noktalı kapalı eğri ile gösterilen bölgede nano telin boyun verdiği ve sonrasında zorlanmanın arttırılmasıyla nano telde kopmanın meydana geldiği görülmektedir.

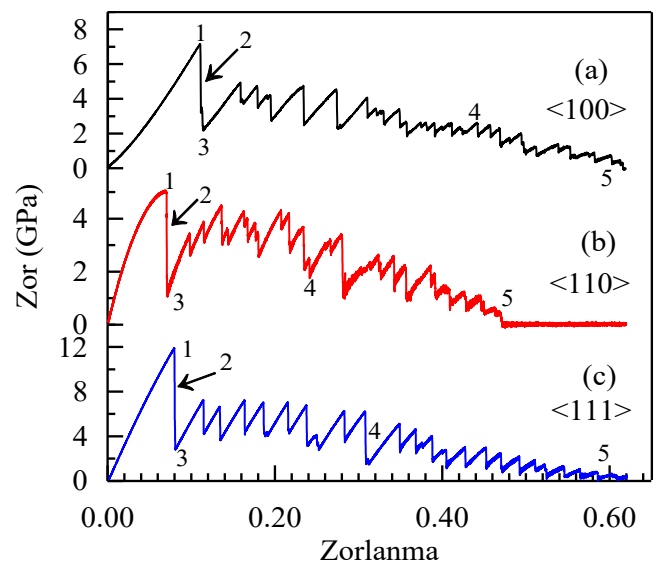

Şekil 5: Farklı kristal yönelimli nano teller için $10 \mathrm{~K}$ sıcaklık değerlerinde elde edilen zorzorlanma eğrileri.

Ayrıca Şekil 7'de akma noktasında [100] doğrultusu boyunca elde edilen nano telin atomik konumları verilmiștir. Akma noktasında elde edilen bu yüzey atomlarının yerleşiminde ikizlenmeler, mikro ikizler ve kayma düzlemleri açıç̧a görülmektedir. Germe işlemi esnasında ikizlenme deformasyonu $<100>$ nano telinin plastik deformasyonunda önemli bir rol oynamaktadır [18]. 


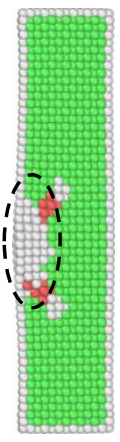

(a)

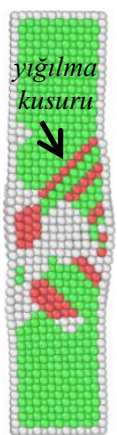

(b)

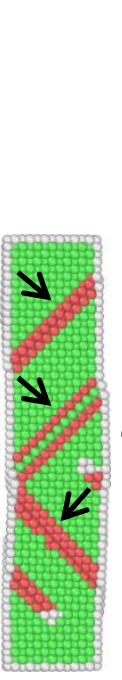

(c)



(d) (e)

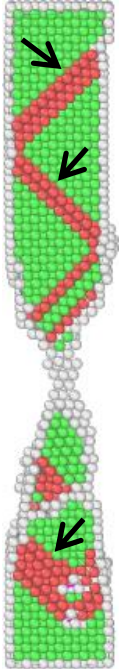

Şekil 6: $<100>\mathrm{Cu}$ nano telinin (100) düzlem kesitinden farklı zorlanma değerlerinde elde edilen atomik görüntüleri.

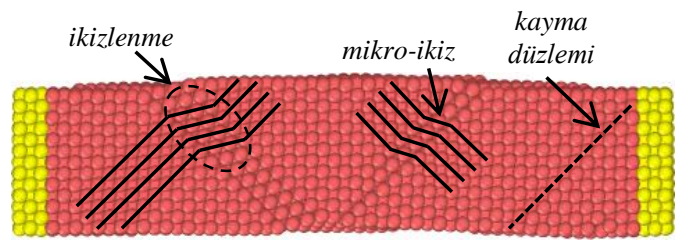

Şekil 7: Akma noktasında $<100>\mathrm{Cu}$ nano telinin [100] doğrultusu boyunca elde edilen yüzey atomik konumları.

Şekil 8'de $<110>$ Cu nano telinin farklı zorlanma değerleri altında (100) düzlem kesitinden elde edilen atomik konumları verilmiştir. Şekil 8(a)'da akma zoruna karşıllı gelen zorlanma değerinde (Şekil 5(b)'de 1 numara) kusursuz fcc yapının korunamadığı, yapı içerisinde beyaz renkli atomların kümelendiği bölgede ilk dislokasyon çekirdeklerinin oluşmaya başladığı söylenebilir. Şekil 8(b-c)'de, (sırasıyla Şekil 5(b) de 2 ve 3 numara) çekirdeklenen kısmi dislokasyonların $\{111\}$ kayma düzlemi boyunca nano telin kesiti boyunca zigzak çizerek ilerlediği ve bu şekilde fcc yapıda hcp atomlarından (kırmızı renkli atomlar) oluşan

yığılma kusurlarının meydana geldiği tespit edilmiștir. Yapı içerisinde olușan bu yı̆̆lma kusurları şekilde oklarla gösterilmiştir. Şekil 5(b)'de 4 numaralı noktaya karşılık gelen zorlanma değerinde nano telin boyun vermeye başladığı Şekil 8(d)'de açıkça görülmektedir. Zorlanma değerinin arttırılıp 5 numaralı noktaya ulaşıldığında Şekil 8(e)' de görüldüğü gibi nano tel tek bir atom teması oluştuktan sonra kopmuștur. Model nano tel yapısında boyun vermenin başladığı zorlanma değerinden kopmanın meydana geldiği zorlanma değerine kadar boyun bölgesi haricinde yeni yığılım kusurları meydana gelmemiștir.

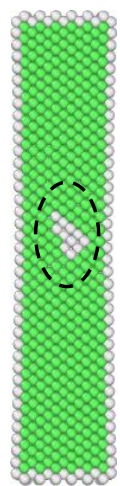

(a)

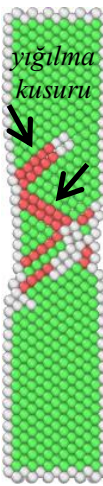

(b)

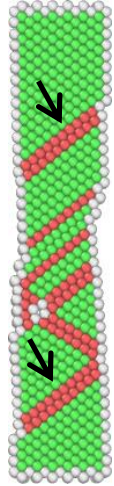

(c)



(d)

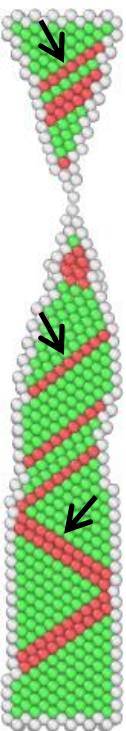

(e)
Şekil 8: <110> Cu nano telinin (100) düzlem kesitinden farklı zorlanma değerlerinde elde edilen atomik görüntüleri.

Şekil 9'da akma noktasında [100] doğrultusu boyunca nano tel yüzeyinin atomik konumları verilmiştir. Nano tel yapısının yüzeyinde ikizlenme ve kayma düzlemlerinin oluştuğu açlkça görülmektedir.

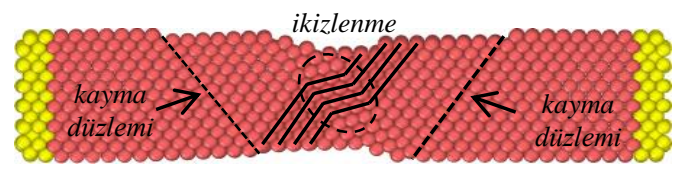

Şekil 9: Akma noktasında $<110>\mathrm{Cu}$ nano telinin [100] doğrultusu boyunca elde edilen atomik konumları.

Şekil 10 (a-e)'da <111> Cu nano telinin gerilme deformasyonu esnasında (100) düzlem kesitinden elde edilen atomik görüntüleri verilmiştir. Şekil 10(a)' da akma noktasında 
(Şekil 5 (c) de 1 numara) elde edilen atomik görüntüden plastik deformasyonun başlangıcında yapı içerisinde hcp atomlarının bir araya gelerek oluşturduğu yığılma kusur düzlemi görülmektedir. Zorlanma değeri artıp Şekil 5 (c) de sırasıyla 2 ve 3 numaralı bölgeye ulaşıldığında, "diğer" olarak adlandırılan tanımsız atomların bulunduğu yüzey bölgesinde kısmi dislokasyonların çekirdeklenmeye başladığı ve yığılım kusurlarının yapı içerisinde yayıldığı Şekil 10 (b-c)'de belirlenmiştir.



(a)

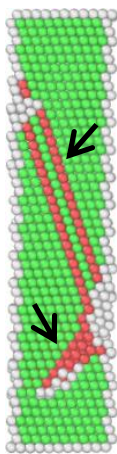

(b)

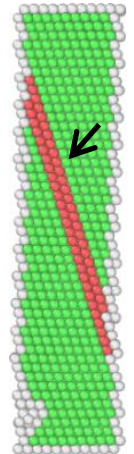

(c)

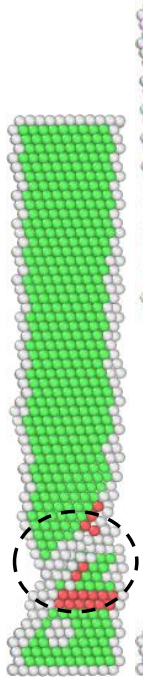

(d)



(e)

Șekil 10: <111> Cu nano telinin (100) düzlem kesitinden farklı zorlanma değerlerinde elde edilen atomik görüntüleri.

Bununla birlikte yüzeyde çekirdeklenmeye bașlayan dislokasyonların yüzeyde kayma düzleminin oluşmasına yol açtığı Şekil 11 de açlkça görülmektedir. $<100>$ ve $<110>\mathrm{Cu}$ nano telleriyle karşılaştırıldığında $<111>$ nano telinin yüzeyinde herhangi bir ikizlenme deformasyonu gözlemlenmemiștir. Şekil 10(de) de nano tele uygulanan zorlanma değerinin artışı dislokasyon aktivitesini arttırdığından dolayı boyun bölgesi oluşmakta ve devam eden süreçte kopma gerçekleşmektedir. Nano tel boyun vermeye başladığında tanımsız atomların sayısı artmakta ve telin sünmesi ile en yüksek değerine ulașmaktadır. Nano tel boyun vermeye başladıktan sonra kopma gerçekleșene kadar uygulanan gerilme işlemi esnasında yapı içerinde herhangi bir yığılım kusuru gözlemlenmemiștir.

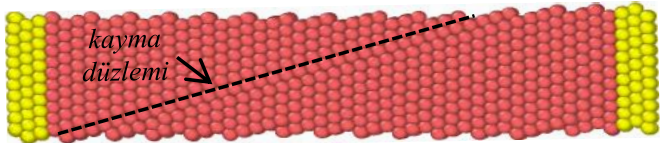

Şekil 11: Akma noktasında <111> Cu nano telinin [100] doğrultusu boyunca elde edilen atomik konumları.

\section{Sonuç}

$\mathrm{Bu}$ çalıșmada $1 \times 10^{10} \mathrm{~s}^{-1}$ zorlanma oranı ile gerilme deformasyonu uygulanan $\mathrm{Cu}$ nano telinin mekanik davranışlarına sıcaklığın ve farklı kristal yönelimlerinin etkisi incelendi. Hem elastik hem de plastik özelliklerin kristal yöneliminden etkilendiği belirlendi. Elastiklik modülünün kristal yönelimine kuvvetli bir şekilde bağlı olduğu ve $<111>\mathrm{Cu}$ nano teli için en büyük değere, <100> nano teli için en küçük değere sahip olduğu tespit edildi. Ayrıca elastiklik modülünün bütün yönelimler için sıcaklıktaki artışla doğrusal bir azalma gösterdiği belirlendi. Bununla birlikte akma zorunun da kristal yönelimine bağlılık gösterdiği, buna karşılık sıcaklık artışıyla doğrusal olmayan bir azalma içerisinde olduğu görüldü. $\mathrm{Cu}$ nano telinde meydana gelen yapısal gelişim ve deformasyon davranışını incelemek için CNA analizi kullanıldı. $<100>,<110>$ ve $<111>$ yönelimleri için genel olarak plastik deformasyonun dislokasyonlar ve yığılım kusurlarının oluşumu şeklinde gerçekleştiği tespit edildi. $<111>$ nano teli haricinde diğer nano tellerde ikiz yapıları belirlendi. $<100>$ ve $<111>$ nano telleri ile karşılaştırıldığında <110> nano telinin boyun bölgesinde üç atom uzunluğunda ince bir atomik zincir oluşturduktan sonra kopmanın meydana geldiği görüldü. Buna göre $<110>\mathrm{Cu}$ nano telinin diğer yönelimli nano tellere göre daha süneklik bir yapı gösterdiği ve çok ince nano tellerin üretilmesi için daha uygun olduğu söylenebilir.

\section{Kaynakça}

[1] Diao, J., Gall, K., Dunn, M.L. 2004. Yield strength asymmetry in metal nanowires, Nano Lett, 4, pp. 1863-1867. doi.org/10.1021/nl0489992

[2] Tosatti, E., Prestipino, S., Kostlmeier, S., Dal Corso, A., Di Tolla, F.D. 2001. String tension and stability of magic tip-suspended nanowires, Science, 291, pp. 288-290. doi: 10.1126/science.291.5502.288

[3] Kondo, Y., Takayanagi, K. 1997. Gold nanobridge stabilized by surface structure, Phys. Rev. Lett. 79 (18),3455-3458.

doi.org/10.1103/PhysRevLett.79.3455 
4] Pasquier, A., Unalan, H. E., Kanwal, A., Miller, S. Chhowalla, M. 2005. Conducting and transparent single-wall carbon nanotube electrodes for polymer-fullerene solar cells, Appl. Phys. Lett., 87, 203511. doi.org/10.1063/1.2132065

[5] Lee, K., Wu, Z., Chen, Z., Ren, F., Pearton, S. J., Rinzler, A. G. 2004. Single wall carbon nanotubes for p-type ohmic contacts to GaN light-emitting diode, Nano Lett., 4, 911-914. doi.org/10.1021/nl0496522

[6] Li, J., Hu, L., Wang, L., Zhou, Y., Gruner, G., Marks, T. J. 2006. Organic light-emitting diodes having carbon nanotube anodes, Nano Lett., 6, 2472-2477. doi.org/10.1021/nl061616a

[7] Sainath, G., Choudhary, B.K. 2016. Orientation dependent deformation behaviour of bcc iron nanowires, Computational Materials Science, 111, pp. doi.org/10.1016/j.commatsci.2015.09.055

[8] Wen, Y.H., Zhang, Y., Wang, Q., Zheng J.C., Zhu, Z.Z 2010. Orientation-dependent mechanical properties of $\mathrm{Au}$ nanowires, Computational Materials Science, 48 , pp. doi.org/10.1016/j.commatsci.2010.02.015

[9] Kizuka, T. 1998. Atomistic visualization of deformation in gold, Phys. Rev. B, 57 (18), pp. 11158-11163. doi.org/10.1103/PhysRevB.57.11158

[10] Tschopp, M.A., McDowell, D.L. 2007. Tensioncompression asymmetry in homogeneous dislocation nucleation in single crystal copper, Appl. Phys. Lett., 90, 121916. doi.org/10.1063/1.2715137

[11] Tschopp, M.A., McDowell, D.L. 2008. Influence of single crystal orientation on homogeneous dislocation nucleation under uniaxial loading, J. Mech. Phys. Solids, 56, pp. 1806-1830. doi.org/10.1016/j.jmps.2007.11.012

[12] Jing, Y., Meng, Q., Zhao, W. 2009. Molcular Dynamics simulations of the tensile and melting behaviours of silicon nanowires, Physica E, 41, pp. 685-689. doi.org/10.1016/j.physe.2008.11.006

[13] Katakam, K. C., Yedla, N. 2021. Influence of orientation and temperature on the mechanical properties and deformation behavior of nickel nanowire under bending: A large scale molecular dynamics simulation, Materials Today: Proceedings, 39 ,

$$
\text { pp. }
$$

1727-1732 doi.org/10.1016/j.matpr.2020.06.302

[14] Jelinek, P., Perez, R., Ortega, J., Flores, F. 2003. Firstprinciples simulations of the stretching and final breaking of $\mathrm{Al}$ nanowires: Mechanical properties and electrical conductance, Phys.Rev. B., 68, 085403. doi.org/10.1103/PhysRevB.68.085403

[15] Cai, J., Ye, Y.Y. 1996. Simple analytical embeddedatom-potential model including a long-range force for fcc metals and their alloys, Phys. Rev. B, 54, 8398. doi.org/10.1103/PhysRevB.54.8398

[16] Tolpin, K.A., Bachurin, V.I., Yurasova, V.E. 2012. Features of energy dependence of NiPd sputtering for various ion irradiation angles, Nucl. Instrum. Methods Phys. Res. B, 273, pp. 76-79. doi.org/10.1016/j.nimb.2011.07.043

[17] Hong, Z.H., Fang, T.H.,Hwang,S.F. 2011. Phase transformation of stress-induced zinc oxide nanobelts using molecular dynamics, Computational
Materials Science, 50, pp. 1994-1950. doi.org/10.1016/j.commatsci.2011.01.049

[18] Gao, Y., Wang, H., Zhao, J., Sun, C., Wang, F. 2011. Anisotropic and temperature effects on mechanical properties of copper nanowires under tensile loading, Computational Materials Science, 50, pp. 3032-3037. 10.1016/j.commatsci.2011.05.023

[19] Zhang, L., Lu, C., Tieu, A.K. 2018. Nonlinear elastic response of singel crystal $\mathrm{Cu}$ under uniaxial loading by molecular dynamics study, Materials Letters, 227, $\quad$ pp. 236-239. doi.org/10.1016/j.matlet.2018.05.094

[20] Sarangi, S.S. 2021. Study on Young's modulus of metallic nanowires using classical molecular dynamics simulations, Materials Today: Proceeding s, 41, pp. 413-415. doi.org/10.1016/j.matpr.2020.09.800

[21] Xu, W., Kim, W.K. 2019. Molecular dynamics simulation of the uniaxial tensile test of silicon nanowires using the MEAM potential, Mechanics of Materials, 137, 103140. doi.org/10.1016/j.mechmat.2019.103140

[22] Alian, A.R., Ju, Y., Muguid, S.A. 2019. Comprehensive atomistic modeling of copper nanowires-based surface connectors, Materials and Design, 175, 107812. doi.org/10.1016/j.matdes.2019.107812

[23] http://lammps.sandia.gov/.LAMMPS Molecular Dynamics Simulator (Erisim Tarihi:02.04.2021).

[24] Kazanc, S. 2013. The effects on the lattice dynamical properties of the temperature and pressure in random NiPd alloy, Can. J. Phys., 91 (10), pp.833838. doi:10.1139/cjp-2013-0090

[25] Kazanc, S., Ozgen, S., Adiguzel, O. 2003. Pressure effects on martensitic transformation under quenching process in a molecular dynamics model of NiAl alloy, Physica B, 334(3-4), pp. 375-381. doi:10.1016/S0921-4526(03)00101-7

[26] Foiles, S.M., Baskes, M.I., Daw, M.S. 1986, Embedded-atom-method functions for the fcc metals $\mathrm{Cu}, \mathrm{Ag}, \mathrm{Au}, \mathrm{Ni}, \mathrm{Pd}, \mathrm{Pt}$, and their alloys, Phys. Rev. B, 33, 7983. doi.org/10.1103/PhysRevB.33.7983

[27] Malins, A., Williams, S.R., Eggers, J., Royall, C.P. 2013. Identification of structure in condensed matter with the topological cluster classification, The Jouurnal of Chemical Physics, 139, 234506. doi.org/10.1063/1.4832897

[28] Stukowski, A. 2012. Structure identification methods for atomistic simulations of crystalline materials, Modelling and Simulation in Materials Science and Engineering, 20, 045021. doi.org/10.1088/0965-0393/20/4/045021

[29] Stukowski, A. 2010. Visualization and analysis of atomistic simulation data with OVITO-the Open Visualization Tool, Modelling and Simulation in Materials Science and Engineering, 18(1), 015012. doi:10.1088/0965-0393/18/1/015012

[30] Wu, H.A. 2006, Molecular dynamics study of the mechanism of metal nanowires at finite temperature, European Journal of Mechanics A/Solids, 25, pp. 370-377. doi.org/10.1016/j.euromechsol.2005.11.008

[31] Sanders, P.G., Eastman, J.A., Weertman J.R. 1997, Elastic and Tensile Behavior of Nanocrystalline 
DEÜ FMD 24(70), 19-28, 2022

Copper and Palladium, Acta Mater., 45(10), pp. 4019-4025. doi:10.1016/S1359-6454(97)00092-X

[32] Wen, Y. H., Zhu, Z. Z., Zhu, R. Z. 2008. Molecular dynamics study of the mechanical behavior of nickel nanowire: Strain rate effects, Computational Materials Science, 41, 553-560. doi.org/10.1016/j.commatsci.2007.05.012

[33] Fang, R., Wang, W., Guo, L., Zhang, K., Zhang, X., Li, H. 2020. Atomic insight into the solidification of $\mathrm{Cu}$ melt confined in graphene Nanoslits. Journal of
Growth,
532 ,
125382.

Crystal

doi.org/10.1016/j.jcrysgro.2019.125382 